\title{
A case of cilioretinal artery occlusion resembling hemicentral retinal artery occlusion
}

This article was published in the following Dove Press journal:

Clinical Ophthalmology

22 November 2012

Number of times this article has been viewed

\author{
Shinji Makino \\ Yuriko Ohkawara \\ Yukihiro Sato \\ Department of Ophthalmology, Jichi \\ Medical University, Shimotsuke, \\ Tochigi, Japan
}

\begin{abstract}
A 77-year-old man presented with an inferior hemivisual field defect in the left eye. Funduscopy revealed well demarcated retinal edema of the superior quadrant resembling hemicentral retinal artery occlusion. Further, the upper and inferior retinal arteries emerged separately from the optic disc. Fluorescein angiography demonstrated a marked filling delay of the upper retinal artery. We repeated fluorescein angiography, which showed that the involved upper retinal artery was a cilioretinal artery having an earlier dye appearance than the lower retinal artery. We suggest that when cases of hemicentral retinal artery occlusion are encountered, vascular architecture at the optic disc should be evaluated carefully.

Keywords: cilioretinal artery occlusion, hemicentral retinal artery occlusion, fluorescein fundus angiography
\end{abstract}

\section{Introduction}

Commonly, cilioretinal arteries extend to the macula from the optic disc. In rare instances, they extend to the superotemporal and superonasal regions. ${ }^{1}$ Clinically evident cilioretinal artery occlusions, thought to be quite rare, appear to comprise about $5.3 \%-7.1 \%$ of all retinal artery occlusions. ${ }^{2,3}$ To our knowledge, there have been few reports in the literature presenting a cilioretinal artery occlusion involving the superotemporal and superonasal regions. ${ }^{4}$ Herein, we report a case of cilioretinal artery occlusion resembling hemicentral retinal artery occlusion.

\section{Case report}

A 77-year-old man was referred to the Jichi Medical University Hospital 3 days after developing a sudden, painless, inferior hemivisual field defect in the left eye on waking from sleep. His personal and family histories were unremarkable. On ophthalmic examination, best-corrected visual acuity in the right eye was 20/20 with $+0.50 \mathrm{D}+0.75 \mathrm{D} \times 20^{\circ}$ and in the left eye acuity was $18 / 20$, which was noncorrigent. Ocular pressures were normal. Slit lamp examination showed cortical opacities in both lenses. Funduscopy of the left eye showed well demarcated retinal edema of the superior quadrant, sparing the fovea (Figure 1). Additionally, the upper and inferior retinal arteries emerged separately from the optic disc. Furthermore, the upper retinal artery showed apparent narrowing. Fluorescein angiography demonstrated a marked filling delay of the upper retinal artery (Figure 2A and B). Blood pressure was $111 / 66 \mathrm{mmHg}$. His blood laboratory findings, electrocardiogram, and chest $\mathrm{x}$-ray were unremarkable. We initially diagnosed the disease as a hemicentral retinal artery occlusion. Ocular massage and paracentesis were performed. Systemic administration
Correspondence: Shinji Makino Department of Ophthalmology, Jich Medical University, 33 I I-I Yakushiji, Shimotsuke, Tochigi 329-0498, Japan

Tel +81285587382

Fax +81285448365

Email makichan@jichi.ac.jp 


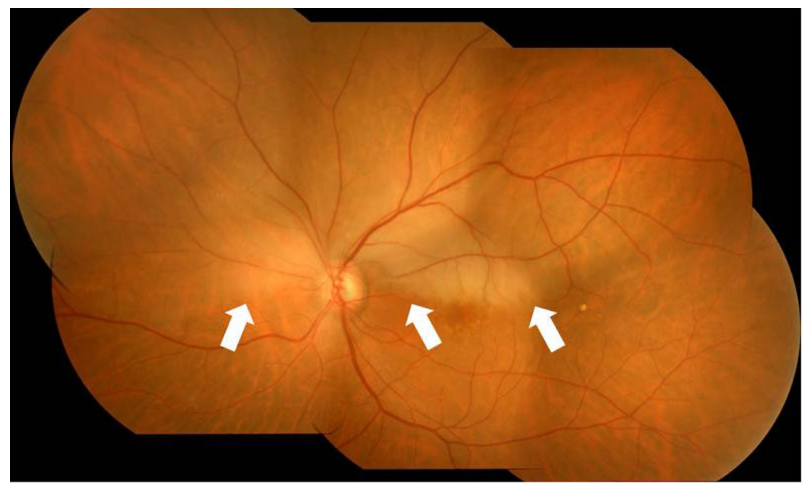

Figure I Left fundus photograph at the first visit showing retinal edema of the superior quadrant (arrow), sparing the fovea.

of a vasodilator drug and an antiplatelet agent were started after the initial examination. Two weeks after initiation of therapy, visual acuity in the left eye improved to 20/16, and the retinal edema disappeared. One month after the initial visit, repeat fluorescein angiography showed remarkable improvement in fluorescein filling of the upper retinal artery, which started almost at the same time as the choroidal flush. Furthermore, dye in the upper retinal artery appeared earlier than in the lower retinal artery (Figure 3A and B). Based on the above results, we diagnosed that the involved upper retinal artery was a cilioretinal artery. He continues administration of an antiplatelet agent. There was no recurrence of retinal vascular occlusion, cardiovascular events, or stroke.

\section{Discussion}

Generally, cilioretinal arteries have been shown to originate from short posterior ciliary arteries, and they appear ophthalmoscopically to emerge from the optic disc or disc margin separately from the central retinal artery or its branches. ${ }^{5}$ Previously, cilioretinal arteries had been identified by their characteristic hook appearance on ophthalmoscopy. ${ }^{1}$ Sodeno $^{1}$ examined rapid serial fluorescein angiograms in 956 cases to evaluate the frequency and characteristic features of the cilioretinal artery. In that study, the following
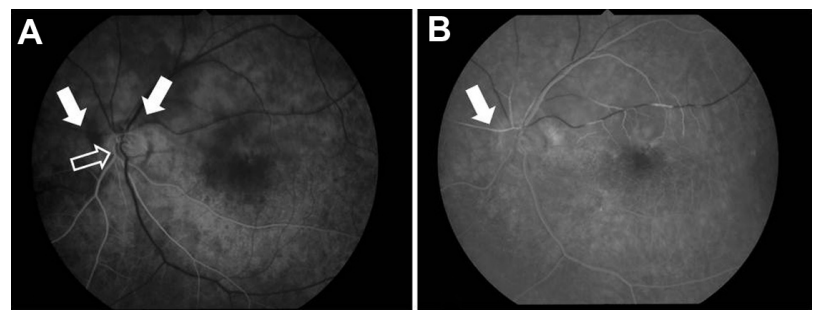

Figure 2 Initial left fluorescein angiography demonstrated a marked filling delay of the upper retinal artery (arrow). The framed arrow indicates the lower retinal artery. (A) 17.7 seconds and (B) 36.5 seconds after injection.

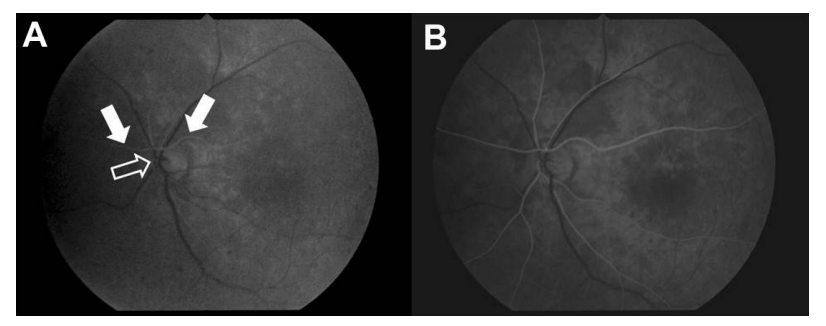

Figure 3 Left fundus fluorescein angiography one month after the initial visit demonstrated an earlier dye appearance in the upper retinal artery (arrow) than in the lower retinal artery (framed arrow) at II.9 seconds (A) and 12.3 seconds (B) after injection.

two fluorescein angiographic features served as diagnostic criteria for the cilioretinal artery: significantly earlier dye appearance than in the central retinal artery (ie, at almost the same time as the choroidal flush) and participation in the microcirculation of the optic disc (ie, cilioretinal arteries directly supplying the microcirculation of the disc). The presence of the cilioretinal artery was confirmed in 379 of the 956 eyes (39.6\%). Furthermore, its distribution was reported as follows: $71.0 \%$ extended to the macula from the optic disc, while $4.7 \%$ extended to the superotemporal and superonasal regions. ${ }^{1}$ Recently, Liu et $\mathrm{al}^{6}$ examined patients using a 45 degree nonmydriatic fundus camera to estimate the incidence and location of cilioretinal arteries. The presence of cilioretinal arteries were $35.0 \%$ in 876 of all subjects and $18.5 \%$ in 923 of all the eyes. Furthermore, of the total number of cilioretinal arteries, $78.3 \%$ were located temporally, $14.8 \%$ were located nasally, and $6.9 \%$ were located bilaterally.

In high magnification images of the left fundus and fluorescein angiography at the optic disc (Figure 4A-C), the difference between the origin and time of dye appearance in the upper and lower retinal arteries was clearly defined, demonstrating that the upper retinal artery involved was

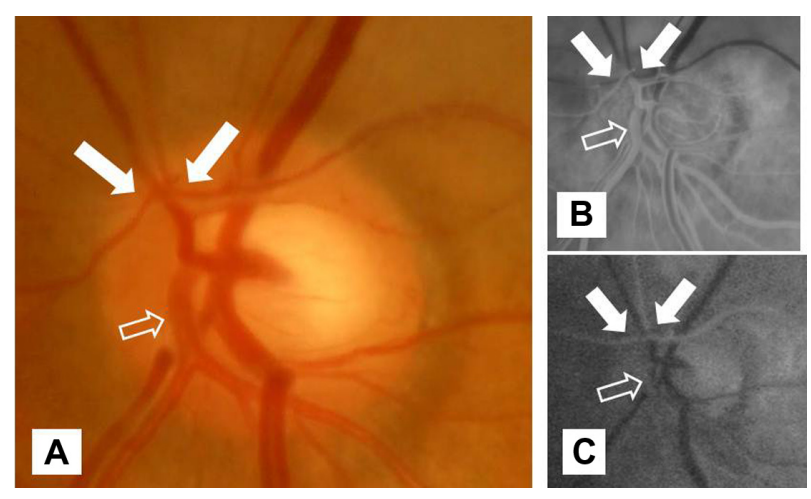

Figure 4 High magnification images of left fundus (A) and left fundus fluorescein angiography [(B) initial visit, (C) one month after the initial visit] at the optic disc. Note: These images clearly define the difference between upper (arrow) and lower (framed arrow) retinal arteries. 
a cilioretinal artery. However, it is not clear where this cilioretinal artery entered at the prelaminar region. Further cases are necessary to answer this question.

Mizuno et $\mathrm{al}^{5}$ described a case of nonarteritic anterior ischemic optic neuropathy with cilioretinal artery occlusion. Their fundus changes were very similar to those seen in our case, ie, separate emergence and a difference in dye appearance on fluorescein angiography in the upper and inferior retinal artery from the optic disc. Rishi et $\mathrm{al}^{7}$ described hemicentral retinal artery occlusion in young adults. They reported some images that are similar to those reported by Mizuno et al, ${ }^{5}$ and are also similar to our case, so we speculate that the upper artery in their case was a cilioretinal artery, whereas the lower one might have been the true central retinal artery.

In our patient, no emboli could be seen on fluorescein angiography, but slugged dye flow in this artery was detected (Figure 2B). Schmidt et $\mathrm{al}^{3}$ described visible emboli in the retinal arteries of patients with branch retinal artery occlusion $(47 \%)$ or hemicentral retinal artery occlusion (41\%), which occurred more often than in patients with central retinal artery occlusion (11\%). The embolus might have caused the condition in the patient but migrated and disappeared by the time the eye was examined. Moreover, a fall in blood pressure during sleep is a well established physiological phenomenon. We think that the other possible reason for the occlusion might have been nocturnal arterial hypotension.
In conclusion, we think that some cases of cilioretinal artery occlusion are similar to hemicentral retinal artery occlusion. Thus, when cases of hemicentral retinal artery occlusion are encountered, vascular architecture at the optic disc should be evaluated carefully in fundus photographs and with fluorescein angiography.

\section{Disclosure}

The authors report no conflicts of interest in relation to this work.

\section{References}

1. Sodeno Y. Cilioretinal artery and the microcirculation of the optic disc. Nihon Ganka Gakkai Zasshi. 1974;78:561-575. Japanese.

2. Brown GC, Shields JA. Cilioretinal arteries and retinal arterial occlusion. Arch Ophthalmol. 1979;97:84-92.

3. Schmidt D, Schumacher M, Feltgen N. Circadian incidence of non-inflammatory retinal artery occlusions. Graefes Arch Clin Exp Ophthalmol. 2009;37:491-494.

4. Hayreh SS. Acute retinal arterial occlusive disorders. Prog Retin Eye Res. 2011;30:359-394.

5. Mizuno K, Sasaoka M, Sasoh M, Uji Y. A case of nonarteritic anterior ischemic optic neuropathy with cilioretinal artery occlusion. Nihon Ganka Gakkai Zasshi. 1995;99:855-860. Japanese.

6. Liu L, Liu LM, Chen L. Incidence of cilioretinal arteries in Chinese Han population. Int J Ophthalmol. 2011;4:323-325.

7. Rishi P, Rishi E, Sharma T, Mahajan S. Hemi-central retinal artery occlusion in young adults. Indian J Ophthalmol. 2010;58:425-432.
Clinical Ophthalmology

\section{Publish your work in this journal}

Clinical Ophthalmology is an international, peer-reviewed journal covering all subspecialties within ophthalmology. Key topics include: Optometry; Visual science; Pharmacology and drug therapy in eye diseases; Basic Sciences; Primary and Secondary eye care; Patien Safety and Quality of Care Improvements. This journal is indexed on

Submit your manuscript here: http://www.dovepress.com/clinical-ophthalmology-journal

\section{Dovepress}

PubMed Central and CAS, and is the official journal of The Society of Clinical Ophthalmology (SCO). The manuscript management system is completely online and includes a very quick and fair peer-review system, which is all easy to use. Visit http://www.dovepress.com/ testimonials.php to read real quotes from published authors. 